\title{
Introduction to the mini-review series on bioenergetics and biomembranes authored by participants of the 39th Annual Meeting of the Brazilian Society for Biochemistry and Molecular Biology
}

\author{
Anibal E. Vercesi
}

Published online: 12 February 2011

(C) Springer Science+Business Media, LLC 2011

The content of this issue represents mini-reviews authored by plenary lectures and round table speakers in the field of bioenergetics and biomembranes from the 39th Meeting of the Brazilian Society for Biochemistry and Molecular Biology (SBBq) held in Foz de Iguaçu, Paraná, Brazil, on May 18-21, 2010.

SBBq was founded in 1967 (Bando and Vercesi 2007) and until 1972 biochemistry sessions were organized during the Annual Meetings of the Brazilian Society for the Advancement of Science (SBPC). From 1972 to 2005 the Society organized independent annual meetings in Caxambu, a small town served by several hotels and known for its several mineral water fountains. Caxambu was chosen due to equidistant position from the cities of Belo Horizonte, Rio de Janeiro, São Paulo and Campinas, the centers that, at that time, were responsible for the generation of about $90 \%$ of Brazilian science. The first meeting was attended by about 60 participants including senior scientists, graduate and undergraduate students. Since then, the meetings have grown in number and quality, in a proportion never imagined by the Society's founders. Currently, SBBq has 726 active Ordinary Members, including many of Brazil's most important scientists from different segments of biochemistry and molecular biology, and 353 Associate Members, who are mostly graduate and postdoctoral students.

A. E. Vercesi $(\bowtie)$

Departamento de Patologia Clínica, Faculdade de Ciências

Médicas, Universidade Estadual de Campinas,

Campinas, SP, Brazil

e-mail: anibal@unicamp.br
The interactions with other scientific communities have increased and $\mathrm{SBBq}$ is also a member of the following organizations: Brazilian Society for the Advancement of Science (SBPC), Federation of Brazilian Societies for Experimental Biology (FESBE), Pan-American Association of Biochemistry and Molecular Biology (PABMB) and the International Union of Biochemistry and Molecular Biology (IUBMB). In 2007 the first IUBMB conference in Latin America was held in Salvador, Bahia, Brazil, organized by SBBq and jointly sponsored by PABMB. In 2015 the 44th Annual Meeting of SBBq will be a joint event with the 23rd IUBMB International Congress to be held again in Foz do Iguaçu.

The city of Foz do Iguaçu is located in the State of Paraná, close to the Three Landmark, limit between Brazil, Paraguay and Argentine, where it is possible to appreciate the three countries simultaneously, besides the encounter of the rivers Iguaçu and Paraná. The city possesses a large hotel park, transportation system, support services and places for accomplishment of different events such as scientific Congresses. In addition, it possesses beautiful natural richness, as the Iguaçu National Park, the largest reserve of subtropical river forest declared as Natural Patrimony of the Humanity and where is located the Iguaçu Waterfalls. Near the area is also located Itaipu, the second largest hydroelectric of the world, on the Paraná River.

The Iguaçu Waterfalls (Fig. 1) contains 275 cascades, including the well known Devil's Throat falling from up $80 \mathrm{~m}$, making a $2,700 \mathrm{~m}$ canyon between the neighbouring countries of Brazil and Argentine. The sound from the colossal water volume falling from the heights and hitting the rocks can be heard from miles away and generates a 
Fig. 1 Schematic representation of some mitochondrial pathways linked to cell survival and death surrounded by a panoramic view of the Iguaçu Waterfalls

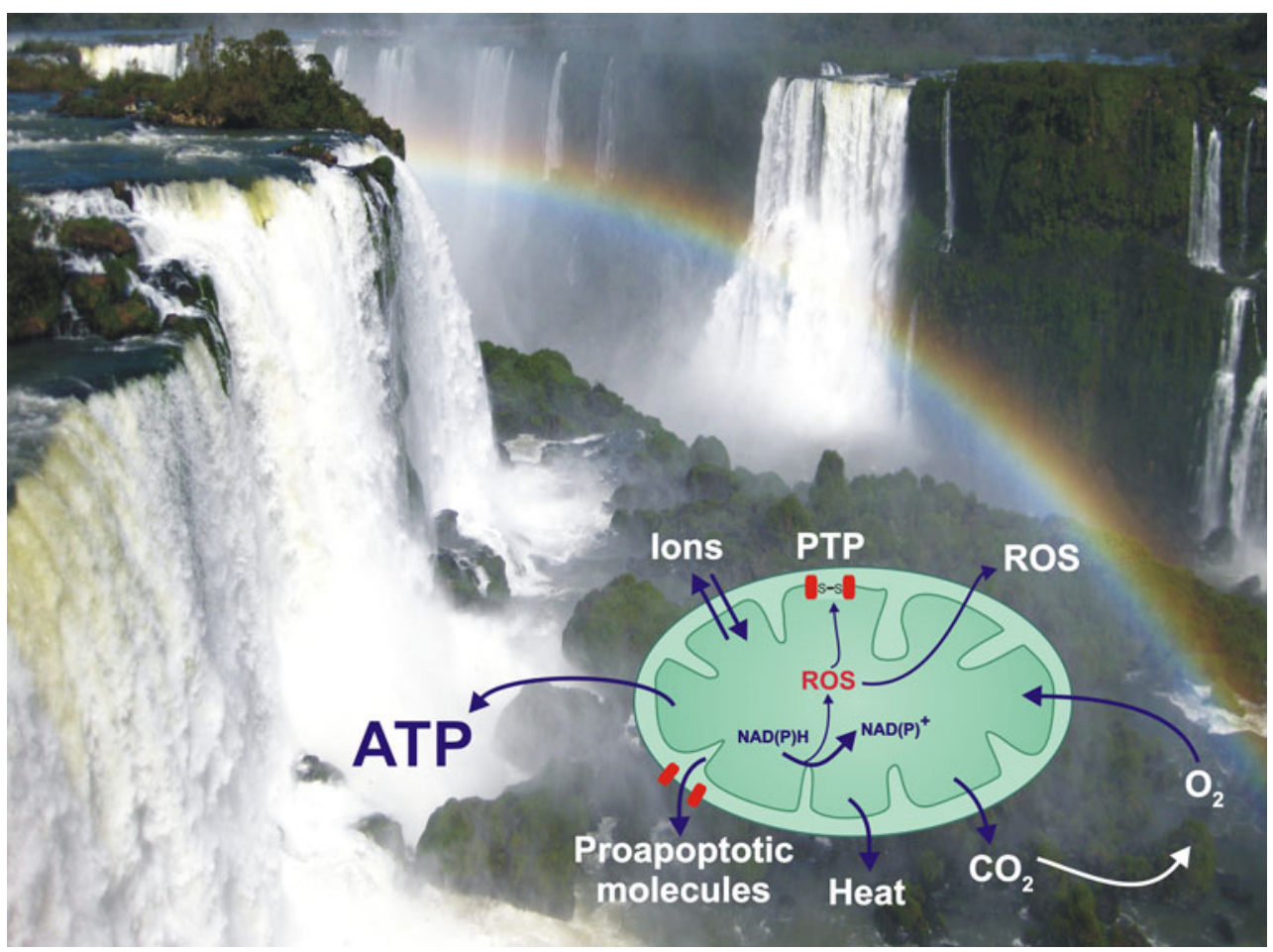

bustling water spray that continuously waters the surrounding forest. The Brazilian side of the Park provides a privileged panoramic view of the falls while the Argentinean side permits a closer contact and integration with the nature, having also the chance to see the jumps from several angles.

The Congress was held during the sunny days of the Brazilian autumn and the participants had the opportunity to combine a sound scientific program with enjoyable visits to the Iguaçu Park. The meeting was attended by 1,798 participants being $96 \%$ Brazilians and $4 \%$ from many different countries (most as invited speakers). There were 1,085 women $(60.4 \%)$, and 1,168 students ( $43 \%$ graduate and $22 \%$ undergraduate students). The scientific program was composed of 14 plenary lectures, 30 round tables and 1,382 posters presentations. The mini-reviews describe the progress made by the authors in the field of bioenergetics and biomembranes, mostly on mitochondrial functions and show a significant participation of the Brazilian biochemists in the field. The topics focus on the mechanisms of free radicals and $\mathrm{Ca}^{2+}$ mediated mitochondrial dysfunction; mitochondrial DNA mutations and redox imbalance in diseases; uncoupling proteins and alternative oxidase gene expression and functions in plants and fungi. In addition, two articles focus on biochemistry of parasites, an undeniably important topic for developing countries.

This mini-review series put together topics on the current understanding of mitochondrial functions indicating that, in addition to be the cell's powerhouse, mitochondria also contain a cell death machinery. Evidence has been provided that mitochondria participate in new functions including cell signalling, injury and death and that mitochondrial DNA mutations may be linked to several diseases (Fig. 1). High levels of matrix $\mathrm{Ca}^{2+}$ stimulate reactive oxygen species production and NADPH and thiols oxidation, and lead to opening of pores in the inner mitochondrial membrane (permeability transition pore, PTP). When PTP opens in a large number of mitochondria, cell death may occur due to the lack of ATP (necrosis). In addition, mitochondrial outer membrane permeabilization (MOMP) induces cell death (apoptosis) through the release of molecules that promote both caspase-dependent and caspase-independent cell death. MOMP itself can occur via processes dependent or independent of PTP opening. Accordingly, mitochondrially-mediated redox imbalance (NADPH and thiols oxidation) may be a common denominator in the pathogenesis of several degenerative diseases rendering mitochondria as important pharmacological targets.

Acknowledgments I would like to thank Cynthia S. Bando for providing the Iguaçu Waterfalls photo, Felipe G. Ravagnani for the artistic work on the Cover Figure and Dr. Roger F. Castilho for critical reading of this Introduction.

\section{Reference}

Bando CS, Vercesi AE (2007) IUBMB Life 59:214-216 